\title{
Meningoencephalitis associated with Mycoplasma pneumoniae
}

\author{
Meningoencefalite associada ao Mycoplasma pneumoniae \\ Isabella Batista de Lalibera ${ }^{1}$, Guilherme de Abreu Silveira ${ }^{2}$, Ricardo Katsuya Toma ${ }^{3}$, \\ Jack Yung $\mathrm{Kuo}^{2}$, Eduardo Juan Troster ${ }^{4}$
}

\begin{abstract}
We report a case of a child with meningoencephalitis of atypical etiology. The patient developed the disease after an infection in the upper airways with unfavorable evolution. The clinical recovery was only possible after the administration of adequate antibiotic therapy for the etiological agent. This case report describes a child with meningoencephalitis of atypical etiology. The patient developed the disease after an infection in the superior airways with negative evolution. The clinical recovery was possible only after the introduction of adequate antibiotic therapy for the etiological agent.
\end{abstract}

Keywords: Mycoplasma pneumoniae; Meningoencephalitis/comlications; Meningoencephalitis/drug therapy; Diagnosis, differential; Case reports

\section{RESUMO}

Este relato de caso descreve uma criança com menignoencefalite de etiologia atípica. A paciente desenvolveu a doença após infecção de vias aéreas superiores, com evolução desfavorável. Houve recuperação clínica somente após introdução de antibioticoterapia adequada para 0 agente etiológico.

Descritores: Mycoplasma pneumoniae; Meningoencefalite/complicações; Meningoencefalite/quimioterapia, Diagnóstico diferencial; Relatos de casos

\section{INTRODUCTION}

Meningoencephalitis constitutes an inflammatory process of the brain parenchyma and meninges. It is characterized by fever, convulsion, irritability, recurrent sleepiness, headache and vomiting ${ }^{(1)}$.
Many etiologic agents can cause the disease, usually vírus, mainly enterovirus and herpes simplex virus 1 and 2. Although, other agents should be considered, such as: atypical bacteria (more specifically mycoplasma pneumoniae) fungi, Rickettsia, protozoa based on host immune factors, symptoms and geographic location $^{(1)}$.

\section{CASE REPORT}

A 5 years and 8 months old previously healthy school girl was referred to our hospital with fever lasting for four days, three days of daytime sleepiness, weakness in lower limbs, difficulty in deambulation and changes in static balance. There was a record of upper airway infection with a skin rash three weeks before symptoms begun.

On admission the patient presented good general condition, sleepiness, Glasgow coma scale score $=15$, isochoric and photo reagent pupils, without sings of menigeal involvement, fever $\left(37,8^{\circ} \mathrm{C}\right)$, blood pressure $107 \times 45 \mathrm{mmHg}$, heart rate of $106 \mathrm{bpm}$, oxygen saturation, $96 \%$ in room air. She presented postural imbalance, negative Romberg test, nasal index and index-index tests with tremor during movements, imbalance in the lower limbs when standing and preserved muscle strength. The patient was referred to the Pediatric Intensive Care Unit for clinical observation and stayed there for 2 days. Afterwards, she was transferred to the Pediatric ward where she stayed until discharge.

\footnotetext{
${ }^{1}$ Pneumology Unit, Instituto da Criança, Faculdade de Medicina, Universidade de São Paulo - USP, Sao Paulo (SP), Brazil.

${ }^{2}$ Hospital Israelita Albert Einstein - HIAE, Sao Paulo (SP), Brazil.

${ }^{3}$ Laboratory of Pediatric Gastroenterology Experimental Surgery, Universidade Federal de São Paulo - UNIFESP, São Paulo (SP), Brazil.

${ }^{4}$ Pediatric Department, Hospital Israelita Albert Einstein - HIAE, São Paulo (SP), Brazil.

Corresponding author: Isabella Batista de Lalibera - Laboratório de Função Pulmonar - Avenida Doutor Enéas de Carvalho Aguiar, 647 - Zip code: $05403-000$ - São Paulo (SP), Brazil - Phone: (11) 2661-8500 E-mail: isalalibera@hotmail.com

Received on: Jul 2, 2011 - Accepted on: Mar 2, 2012

Conflict of interests: None
} 
Additional tests were performed at the time of admission. The blood cell count showed leukocytosis without left shift (leukocytes $17,600 / \mathrm{mm}^{3}$, neutrophils $80 \%$, lymphocytes $15 \%$, monocyte $3 \%$ ); normal platelet count $\left(357.000 / \mathrm{mm}^{3}\right)$; C-reactive protein $35.6 \mathrm{mg} / \mathrm{L}$; skull tomography without changes; cerebrospinal fluid (CSF) compatible with lymphocytic meningitis (leukocytes $350 / \mathrm{mm}^{3}$, segmented $14 \%$, lymphocytes $58 \%$, monocytes $28 \%$ ); serum protein $67 \mathrm{mg} / \mathrm{dL}$, glucose $48 \mathrm{mg} / \mathrm{dL}$, chloride $684 \mathrm{mEq} / \mathrm{L}$, lactic acid $14.6 \mathrm{mg} / \mathrm{dL}$; magnetic resonance showed unspecific signal changes in the pons (rhombencephalitis); electroencephalogram with basal activity slightly disorganized because of diffuse slowing and lack of epileptiform waves. Based on neurologic changes at physical examination and in additional tests, we diagnosed meningoencephalitis of probable viral etiology, initiating the treatment with aciclovir.

The patient's follow up showed slight improvement in sleepiness, but the fever remained. After 5 days of hospital stay new tests were done, and there was partial improvement of cellularity and protein dosage in CSF (leukocytes 231/ $\mathrm{mm}^{3}$, segmented 23\%, lymphocytes $39 \%$, monocytes $32 \%$, glucose $38 \mathrm{mg} / \mathrm{dL}$, protein $55 \mathrm{mg} / \mathrm{dL}$ ), blood cell count had a slightly increase of

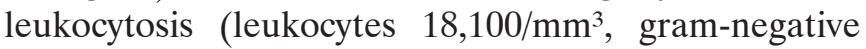
rods $2 \%$, neutrophils $82 \%$, lymphocytes $13 \%$, monocytes $3 \%$ and platelets $407,000 / \mathrm{mm}^{3}$ ).

We associated ceftriaxone and clarithromycin, this last one particularly because the the prior respiratory episode. We conducted serology tests for M. pneumoniae. On the $10^{\text {th }}$ admission day and after five days of antibiotic therapy there was significant improvement in the neurological sings and symptoms as well as on the fever curve.

The serology for herpes virus, cytomegalovirus, enterovirus varicella-zoster and $M$. pneumoniae in the CSF were negative. But, serology for M. pneumoniae in the blood was positive (IgG 1: 1,726 and $\operatorname{IgM} 1$ : 3.452 by the immunoenzymatic assay method). The meningoencephalitis was diagnosed as likely being caused by M. pneumoniae, for this reason we stopped the use of ceftriaxone and continued with clarithromycin and acyclovir to complete the treatment. The patient was discharge after 15 days of hospital stay, although her sleepiness remained. We decided to use corticotherapy with prednisone $2 \mathrm{mg} / \mathrm{kg} / \mathrm{day}$ for 10 days, and gradual reduction of the dosage. An asymptomatic follow up, without neurological sequelae was observed.

\section{DISCUSSION}

M. pneumoniae is a commom cause of respiratory tract infections and is more common in school-age children and adolescents. The incubation period may vary between 1 and 3 weeks. Its transmission is documented only by symptomatic individuals.

Infection may also occur in other sites than the lungs such as skin, heart, joints and nervous system by direct action, production of neurotoxins or autoimmune mechanisms. This latter mechanism is the more accepted specially because $M$. pneumoniae has in its cytoplasm immunogenic substances like glycoproteins ${ }^{(2,3)}$. Some studies show that approximately 2.6 to $4.8 \%$ of patients affected by $M$. pneumoniae have clinical neurological manifestations such as encephalitis (30\%), transverse myelitis $(30 \%)$, meningitis $(20 \%)$, problems in pairs of cranial nerves $(20 \%)$, cerebellitis (14\%), psychiatric changes $(8 \%)$, and $67 \%$ present previous sings of airway infection $^{(3,4)}$.

The diagnosis of neurological infection by $M$. pneumoniae can be made by laboratory tests, being ELISA the serologic test the most commonly used. The chemocytology of the CSF show moderate pleocytosis of lymphomonocytes, high protein and normal glucose levels.

The etiologic agent can be found in these sites in about $2 \%$ of cases ${ }^{(3,5)}$ The antibiotic of choice to treat the pulmonary infection in children is a macrolide, however, there is no consensus regarding the central nervous system treatment. It is well know that such class of antibiotic does not properly penetrate the blood brain barrier. However, because of its bacteriostatic and immunomodulatory effect, and one of the possible physiopathological mechanism of the disease is immunologic, it would be a treatment option. In addition, the use of corticosteroids, adopted in this case, must be always considered as immunosuppression depending on the degree of neurologic involvement ${ }^{(6,7)}$.

\section{CONCLUSION}

The infection by M. Pneumoniae is usually found in the pediatric age, therefore, in the differential diagnosis of neurologic problems, which do not have a fair response to an initial antibiotic therapy, this agent should considered as its cause. The appropriated identification of this atypical agent enables more specific and early treatment.

\section{REFERENCES}

1. Willoughby Jr RE. Encephalitis, meningoencephalitis, and postinfectious encephalomyelitis. In: Long SS, Pickering LK, Prober CG, editors. Principles and practice of pediatric infectious diseases. Philadelphia: Elsevier Science; 2003. p. 291-2. 
2. Foy HM, Kenny GE, Cooney MK, Allan ID, van Belle G. Naturally acquired immunity to pneumonia due to Mycoplasma pneumoniae. J Infect Dis. 1983; 147(6):967-73.

3. Christie LJ, Honarmand S, Talkington DF, Gavali SS, Preas C, Pan CY, et al. Pediatric encephalitis: what is the role of Mycoplasma pneumoniae? Pediatrics. 2007;120(2):305-13.

4. New and notes. Epidemiology: Mycoplasma pneumoniae, 1977. Br Med J. 1978; 1(6114): 725-9.
5. Cherry JD. Mycoplasma and ureaplasma infections. In: Feigin RD, Cherry JD, Demmter-Harrison GJ, Kaplan SL. Textbook of pediatric infectious diseases. 6rd ed. Philadelphia: WB Saunders; 2009. Vol. 2; p. 2685-2714.

6. Narita M. Pathogenesis of neurologic manifestations of Mycoplasma pneumoniae infection. Pediatr Neurol. 2009;41(3):159-66.

7. Daxboeck F, Blacky A, Seidl R, Krause R, Assadian 0. Diagnosis, treatment, and prognosis of Mycoplasma pneumoniae childhood encephalitis: systematic review of 58 cases. J Child Neurol. 2004;19(11):865-71. 